IZA DP No. 5727

Equity and Efficiency in Multi-Worker Firms: Insights from Experimental Economics

Johannes Abeler

Steffen Altmann

Sebastian J. Goerg
Sebastian Kube

Matthias Wibral

May 2011 


\title{
Equity and Efficiency in Multi-Worker Firms: Insights from Experimental Economics
}

\author{
Johannes Abeler \\ University of Nottingham and IZA \\ Steffen Altmann \\ IZA
}

Sebastian J. Goerg

Max-Planck-Institute for Research on Collective Goods

Sebastian Kube

University of Bonn and IZA

Matthias Wibral

University of Bonn and IZA

Discussion Paper No. 5727

May 2011

IZA

P.O. Box 7240

53072 Bonn

Germany

Phone: +49-228-3894-0

Fax: +49-228-3894-180

E-mail: iza@iza.org

\begin{abstract}
Any opinions expressed here are those of the author(s) and not those of IZA. Research published in this series may include views on policy, but the institute itself takes no institutional policy positions.

The Institute for the Study of Labor (IZA) in Bonn is a local and virtual international research center and a place of communication between science, politics and business. IZA is an independent nonprofit organization supported by Deutsche Post Foundation. The center is associated with the University of Bonn and offers a stimulating research environment through its international network, workshops and conferences, data service, project support, research visits and doctoral program. IZA engages in (i) original and internationally competitive research in all fields of labor economics, (ii) development of policy concepts, and (iii) dissemination of research results and concepts to the interested public.
\end{abstract}

IZA Discussion Papers often represent preliminary work and are circulated to encourage discussion. Citation of such a paper should account for its provisional character. A revised version may be available directly from the author. 
IZA Discussion Paper No. 5727

May 2011

\section{ABSTRACT \\ Equity and Efficiency in Multi-Worker Firms: Insights from Experimental Economics ${ }^{*}$}

In this paper, we discuss recent evidence from economic experiments that study the impact of social preferences on workplace behavior. We focus on situations in which a single employer interacts with multiple employees. Traditionally, equity and efficiency have been seen as opposing aims in such work environments: individual pay-for-performance schemes maximize efficiency but might lead to inequitable outcomes. We present findings from laboratory experiments that show under which circumstances partially incomplete contracts can create equitable work environments while at the same time reaching surprisingly efficient outcomes.

JEL Classification: J33, D63, M52, C92, J41

Keywords: incentives, wage setting, equity, gift exchange, reciprocity, incomplete contracts, organizational economics, laboratory experiments

Corresponding author:

Steffen Altmann

IZA

P.O. Box 7240

53072 Bonn

Germany

E-mail: altmann@iza.org

\footnotetext{
* We thank Michael Siekemeier for excellent research assistance.
} 


\section{Introduction}

Economic exchange frequently relies on informal agreements that specify the contracting parties' obligations only imprecisely. Such contractual incompleteness is particularly widespread in the labor market. Fully contingent, explicit contracts are absent in a wide range of industries and occupations. Rather, employment contracts often only stipulate quite general parameters of the work relationship, like fixed salaries, required working times, or vacation entitlements. This does not only imply that many important aspects of an employment relationship - such as the assignment of employees to specific tasksare left unspecified. It also means that workers' payments are often not explicitly tied to their performance. From an economic perspective, this might seem counter-intuitive at first sight. If pay does not depend on performance, workers are left with at least some discretion on whether and how to fulfill their obligations. This in turn can give rise to moral hazard, i.e., worker slacking and other behaviors that are potentially detrimental to the employer.

However, economic models also offer a number of potential explanations for why contractual incompleteness in employment relationships is ubiquitous. A first and rather simple explanation is that it is inherently difficult to objectively measure employees' performance and work effort. Employers and employees might thus decide to include only those obligations in the employment contract which they can actually enforce and verify. Research in contract and game theory has also identified circumstances where it might not be necessary or even undesirable for an employer to connect pay more closely to performance although this would, in principle, be possible. First, employment relations are typically repeated interactions over a long time horizon. Opportunistic behavior in earlier periods can be punished later on. Thus, there is scope for so-called "relational" contracts that are self-enforcing in the sense that the value of future interaction is higher than the short-run gains from opportunistic behavior (MacLeod and Malcomson 1989; Baker et al. 1992). A similar logic applies if employees have concerns

for their future career. If employees are eager to qualify for a better paid job in the 
future, either within the firm (Lazear and Rosen 1981; Rosen 1986) or in other firms (Fama 1980; Holmström 1999; Gibbons and Murphy 1992), they have strong implicit incentives to perform well, even though their current pay is not explicitly tied to performance. Finally, the so called multitasking problem can induce an employer to refrain from using high-powered pay-for-performance schemes. Multitasking problems occur if the employer aims at inducing the employee to engage in multiple tasks, but can only verify performance in a subset of these tasks (Holmström and Milgrom 1991).

Beside these purely pecuniary causes of contractual incompleteness there can also be psychological reasons for why employers do not want or need to use explicit performancebased incentive schemes. Evidence along these lines can be found in recent research on the psychological foundations of incentives. An impressive body of literature in psychology and behavioral economics has demonstrated that employees' behavior does not only depend on the relationship between measured performance and pay. Rather, payfor-performance schemes may have unintended, dysfunctional behavioral consequences if workers are concerned about horizontal or vertical equity (Adams 1965), are intrinsically motivated (Deci 1971; Gneezy and Rustichini 2000), or dislike being controlled (Falk and Kosfeld 2006).

Moreover, moral-hazard problems may potentially be mitigated by preferences for fairness or reciprocity, since workers and employers with social preferences might not exploit existing opportunities for opportunistic behavior. Especially reciprocity, i.e., the willingness to reward kind actions and punish unkind ones even at a cost to oneself, has been discussed as an effective means for eliciting work effort under contractual incompleteness. Consequently, Akerlof (1982) argues that many employment relationships resemble "gift-exchange" relationships, in which firms voluntarily pay high wages and workers voluntarily repay these with effort in excess of the minimum work standard. The introduction of a simple paradigm to study such relationships in the laboratory by Fehr et al. (1993) gave economists a tool to address many of the questions surrounding gift exchange. In the simplest form of this prototypical paradigm, one player (the "employer") interacts with one "employee". The employer pays an upfront wage and has 
to trust that the employee repays the "gift" of a high wage by voluntarily providing a high level of productive work effort. Potential efficiency gains through effort provision, however, will not be realized if all players are rational and selfish: the employee will provide the minimal effort since effort is costly and will only reduce his monetary payoff and, anticipating this, the employer will pay the minimum wage.

However, a large number of papers has demonstrated empirically that employees who feel treated kindly indeed tend to repay a generous wage payment by voluntarily providing high work effort even in one-shot situations where no future gains can be expected (e.g., Fehr et al. 1997; Fehr and Falk 2002; Kube et al. 2011). Reciprocity in employment relationships can also imply that workers who feel treated unfairly withhold work effort, e.g., after an arbitrary wage cut (e.g., Kube et al. 2010; Cohn et al. 2011). Both positive and negative reciprocal reactions illustrate how social preferences might work as a device to enforce incomplete contracts in employment relationships. The mounting evidence on gift exchange and the importance of social preferences in the working place has led to a partial re-assessment of long-standing discussions in labor economics. In particular, it has illustrated that economic efficiency and equity do often not stand in contrast but can be achieved at the same time. By increasing the perceived equity of workers' wages, employers can induce workers to provide higher work effort which in turn can enhance economic efficiency.

In this paper, we present and discuss recent evidence on the impact of social preferences on work behavior. We focus on a selection of studies that use economic experiments to analyze the interaction between a single employer (principal) and multiple employees (agents). ${ }^{1}$ While the majority of gift-exchange studies investigates settings where a principal is matched with a single agent, a multi-agent setting is at the same time more realistic and allows analyzing more nuanced implications of social preferences.

\footnotetext{
${ }^{1}$ We deliberately restrict our attention to a relatively narrow set of studies based on our own work to be able to provide an in-depth perspective on how economic experiments can be used to study the questions of interest. For recent comprehensive reviews on laboratory and field experiments in labor economics, see Charness and Kuhn (2011) and List and Rasul (2011).
} 
Most importantly, it permits to take a more detailed view on workers' perceptions of what constitutes a fair or equitable action by the employer; in particular with respect to the wage received. When an employer interacts with more than one agent, fairness concerns and social comparisons are no longer only relevant along a vertical dimension, i.e., between the employer and the employee. Rather, social comparisons along a horizontal dimension, i.e., between workers on the same layer of the hierarchy, might be crucial for fairness perceptions and worker behavior. Relative wage concerns between co-workers might influence their satisfaction with and reaction to a given wage offer. Wage discrimination between workers will therefore be a recurring theme in this paper. As will become clear, the relation between equity and efficiency becomes more complex in a multi-worker setup.

We center our discussion around four main questions. In Section 2, we present an experiment by Abeler et al. (2010) that analyzes the relative importance of two conflicting fairness principles - wage equality and horizontal equity. In particular, Abeler et al. study whether equal wages are considered fair and look at potentially detrimental consequences of equal wages on performance. In Section 3, we turn to a second question that becomes important when principals interact with more than one agent, namely, whether the principal can observe agents' individual performance or only the outcomes of the group of agents as a whole. We present a recent study by Kleine and Kube (2010) that addresses the question whether reporting (subjective) performance measures can enhance the efficiency of interaction in work groups. Next, we discuss a study by Schneider and Kube (2006) that analyzes how differences in social proximity affect gift exchange in multi-worker firms. In particular, the experiment discussed in Section 4 studies whether principals tend to (unfairly) favor agents with whom they have closer social ties and discusses potential implications for wage transparency within firms. Wage discrimination again plays a role in section 5 where we address the question how workers' fairness perceptions and propensity to exert work effort interact with firms' production technology. In multi-worker firms, workers' individual productivities can be intertwined for technological reasons. In particular, situations exist where it 
can be optimal from an economic perspective to pay differential rewards for equal performance of workers. We present a recent paper by Goerg et al. (2010) that analyzes whether workers acknowledge such technological reasons for wage differentiation, or whether this is generally in conflict with workers' fairness perceptions.

Methodologically, we focus on studies that use economic experiments. ${ }^{2}$ Controlled laboratory experiments have rapidly emerged as a vital component of research in personnel and labor economics. For the questions addressed in this paper, the use of experimental methods has two distinct advantages. First, the laboratory allows tight control over the work environment under consideration. In particular, the experimenter exactly knows the information structure, production functions, and compensation schemes, and he obtains precise measures of variables that are inherently difficult to observe in field setups (e.g., workers' ability and effort levels). Second, the variables of interest can be exogenously varied in different treatment conditions of an experiment. This enables the researcher to identify clear causal effects of variations in, e.g., incentive schemes, production technology, or information conditions. All this allows for rigorous testing of theoretical models on labor market gift exchange. By contrast, this is hardly possible with non-experimental data on workplace behavior. For example, observed variations in wages might be driven by firm size, self-selection of workers, or simply productivity differences. Observed variations in work output might thus not only be caused by worker' effort but by differences in ability or production technology. Studying the fundamentals of gift-exchange relations with observational data is thus quite hard-even if a positive association between wages and effort is observed, this could reflect, e.g., strategic considerations based on reputation and repeated interactions. In the laboratory, these factors can be varied in a controlled fashion (Falk and Heckman 2009). ${ }^{3}$

\footnotetext{
${ }^{2}$ Apart from the economic literature there is a substantial literature in experimental social psychology which studies equity in social exchange. See Mowday (1991) for an overview.

${ }^{3}$ It should be noted that a critical question facing experimental economists is whether behavior inside the laboratory is a good indicator of behavior outside the laboratory. Levitt and List (2007) summarize cases where the lab may understate the importance of social preferences as well as instances
} 


\section{The importance of wage discretion}

The potential of gift exchange as a contract enforcement device is likely to depend on the institutions that shape the employment relation, above all the mode of payment. A key question in this context is how to treat agents relative to each other as this affects the perceived fairness of a pay scheme. Abeler et al. (2010) study this question by analyzing two important fairness principles: horizontal equality and equity.

The specific wage institution they consider is wage equality. Paying equal wages to workers on the same level of a hierarchy is common practice in many firms (e.g., Medoff and Abraham 1980; Baker et al. 1988). Several reasons for equal wages have been brought forward, amongst them increased peer monitoring (Knez and Simester 2001) and lower transaction costs since contracts do not have to be negotiated with every worker individually (see also Prendergast 1999). Most importantly, a concern for fairness has been a main argument invoked to justify equal wages. It has been argued that differential pay of co-workers is considered unfair by workers, causes resentment and envy within the workforce, and ultimately lower performance (Pfeffer and Langton 1993; Bewley 1999). Equality is also often referred to in employer-union bargaining as being a cornerstone of a fair wage scheme.

However, it could be that wage equality hampers the effectiveness of gift exchange. This is likely to be the case if agents do not primarily consider wage equality as fair, but rather care about horizontal equity (Adams 1963). In a work environment, the equity principle demands that a person who exerts higher effort should receive a higher wage compared to his co-worker. ${ }^{4}$ Only when performance of co-workers is the same, do equity and equality coincide. However, in real-life work relations this is likely to be the exception rather than the rule. Whenever workers differ in their performance, horizontal in which the lab might exaggerate their importance. They conclude by emphasizing the importance of interpreting laboratory and field data through the lens of theory.

${ }^{4}$ The idea of proportionality in inputs and outcomes dates at least back to Aristotle's Nicomachean Ethics. 
wage equality violates the equity principle since a higher effort is not rewarded with a higher wage. In other words, if equity is important, the often-heard slogan "equal pay for equal work" also implies "unequal pay for unequal work".

\subsection{Design}

Abeler et al. study the relative importance of these fairness principles by analyzing their implications for work performance and efficiency. They do so in a laboratory experiment in which one principal interacts with two agents. The game played is similar to the gift-exchange game described in the introduction with a reversed move order. In a first stage, each agent chooses the level of costly effort to exert (between 1 and 10). Effort costs are increasing in effort and convex. After observing the agents' effort choices, the principal pays a wage to each agent (between 0 and 100). In the main treatment the principal can choose the level of the wage but she is obliged to pay the same wage to both agents (equal wage treatment or EWT). In the control treatment, she can wage discriminate between the two agents (individual wage treatment or IWT). In both treatments, neither efforts nor wages are contractible, i.e., effort provision and wage payments are voluntary and can not be explicitly enforced. The stage game is repeated twelve times, with principals and agents being randomly rematched in different periods of the game ("stranger design"). The payoff of agents increases in their wage and decreases in their effort level. The principal's payoff increases in the sum of provided efforts and decreases in the wages paid.

As in the bilateral gift-exchange game described in Section 1, if all players are rational and selfish the principal will not pay anything to the agents since wage payments only reduce her monetary payoff. Anticipating this, both agents will provide the minimal effort (i.e., an effort of 1). Neither the reversed move order nor the presence of additional agents changes this standard prediction. In the presence of social preferences, these predictions change. If agents care foremost about wage equality, there should be no treatment difference: principals in the individual wage treatment might anticipate a preference for equal treatment and simply pay the same wage to both agents. However, 


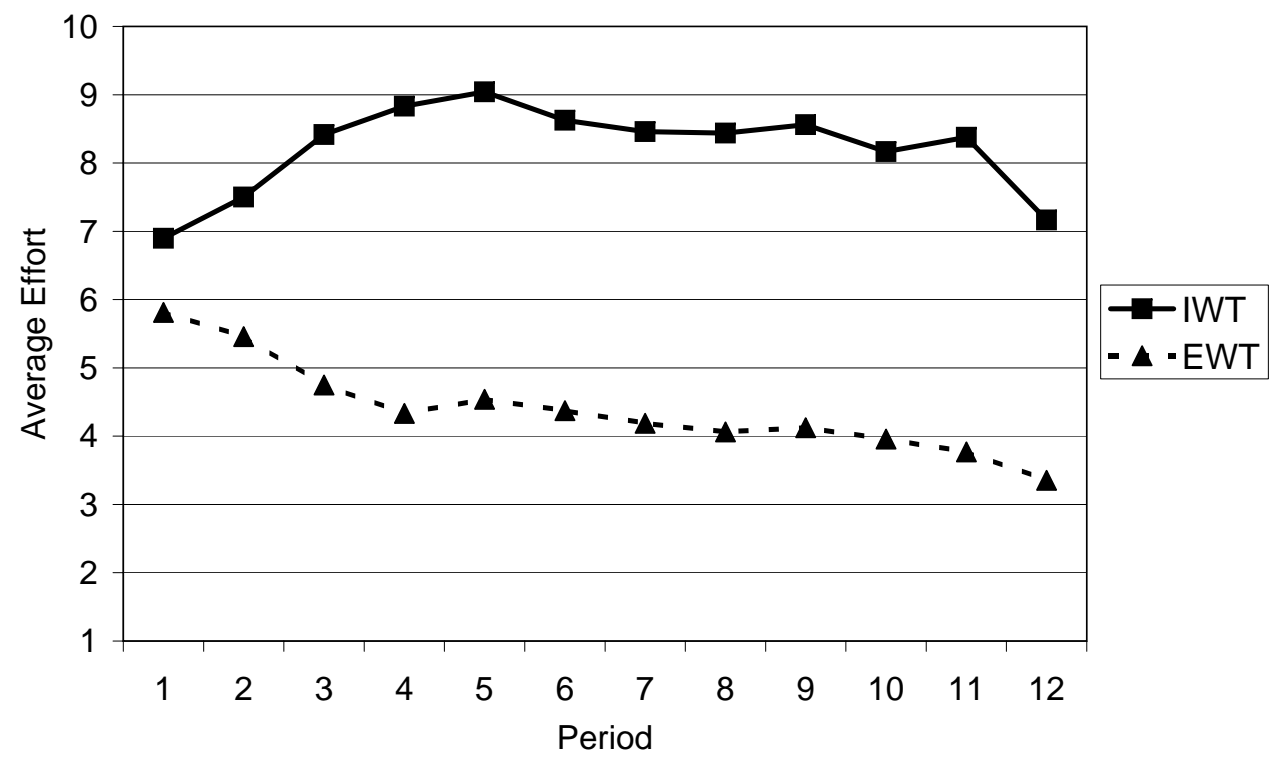

Figure 1: Abeler et al. (2010): Average effort per period.

if equity considerations are more important, one should observe that the EWT elicits lower effort levels than the IWT.

\subsection{Results}

Abeler et al. find that, in both treatments, the agent's individual effort and his own wage are positively correlated which in bilateral gift-exchange experiments was sufficient to establish successful relationships. The monetary incentives, i.e., the average level of wages paid for a given effort level, are also similar in both treatments. Nevertheless, agents' behavior differs substantially between treatments. Agents who are paid equal wages exert significantly lower efforts than agents who are paid individually. Effort levels are nearly twice as high under individual wages, and efforts decline over time when equal wages are paid (see Figure 1). Especially the performance of agents under individual wages shows how powerful gift exchange can be in eliciting work effort: although explicit contract enforcement is not feasible, $80 \%$ of the possible efficiency gains are realized.

The strong differences in efforts suggest that the relative treatment of agents indeed 
plays an important role in the multi-agent environment. More precisely, Abeler et al. demonstrate that equal wages are apparently not reconcilable with agents' horizontal fairness considerations. As the authors show, the frequent violations of the equity principle in the equal wage treatment are able to explain the effort differences between the treatments. In both treatments, agents who exert a higher effort and earn a lower payoff than their co-worker strongly decrease their effort in the subsequent period. However, the norm of equity is violated much more frequently under equal wages (whenever agents' effort levels and thus their effort costs differ). Principals in the individual wage treatment seem to understand the mechanisms of equity quite well. When efforts differ, they do pay different wages, rewarding the harder-working agent with a higher payoff in most cases - and it is in these cases that successful gift-exchange relations between principal and agents are established.

Abeler et al. then turn to analyzing how efforts evolve over time to allow for a deeper understanding of the effects of equal wages. A common informal argument claims that equal wages will be especially detrimental to the motivation of high performers but clean empirical evidence on this hypothesis is scarce. To analyze this hypothesis, Abeler et al. classify agents according to their effort decision in the first period. They define the agent with the highest first-period effort in each matching group as "high-effort provider" and the agent with the lowest effort as "low-effort provider". First-period effort is a good proxy for the intrinsic willingness of a specific agent to exert effort.

Figure 2 follows the high-effort providers and low-effort providers in both treatments and shows their effort decisions over time. In the first period, the groups of high-effort providers and the groups of low-effort providers are close together across treatments. This changes drastically over the course of the experiment. In the individual wage treatment, high-effort providers continue to provide high effort levels. Low-effort providers increase their efforts dramatically up to the level of the high-effort providers and even higher in the last periods. In the equal wage treatment, the dynamics are reversed. Here, the low-effort providers keep their effort provision constant and the high-effort providers reduce their efforts to the level of the low-effort providers. 


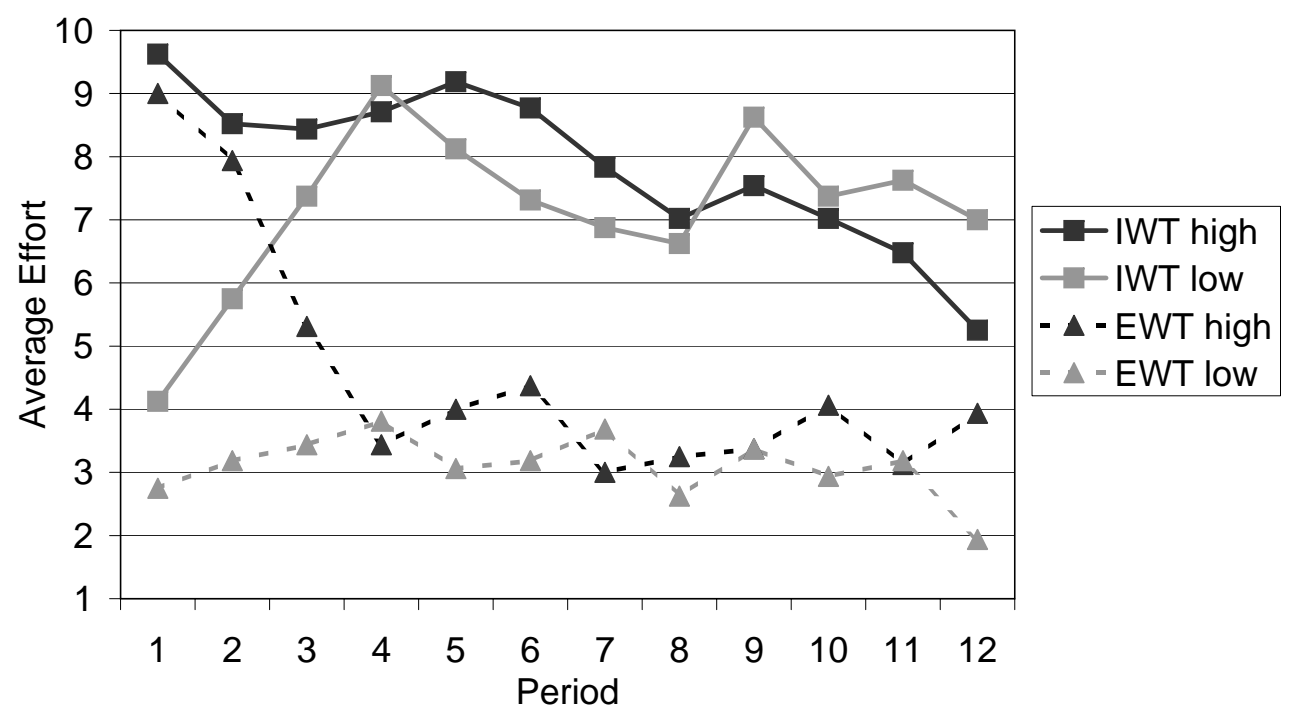

Figure 2: Abeler et al. (2010): Effort decisions of high-effort and low-effort providers.

These dynamics underline the importance of the different non-monetary motives induced by the two wage setting institutions. Agents in the equal wage treatment who are in principle willing to exert high levels of effort seem to get frustrated and lower their efforts over time. On the contrary, under individual wages most principals adhere to the equity principle, and good performance spreads. These results suggest that choosing a wage scheme also influences the social dynamics between the agents. In the experiment, individual wages lead to positive dynamics since agents orientate themselves by the most hard-working agents. In contrast, the equal wage scheme focuses agents' attention on the least motivated agents.

In summary, the results Abeler et al. suggest a psychological rationale for using individual wages. Subjects perceive equal wages for unequal performance as unfair and reduce their effort subsequently. The traditional economic literature on incentive provision in groups comes to a similar conclusion though for a different reason. It is usually argued that the inefficiency of equal wages stems from the fact that marginal products and wages are not aligned. This can lead to free-riding among selfish agents (e.g., Holmström 1982; Erev et al. 1993). Abeler et al. (2010) enlarge the scope of this 
critical view on wage equality: interestingly, in their setup it is precisely the presence of fair-minded agents and not their absence that calls for the use of individual rewards.

Regarding compensation practice in firms, their findings highlight the importance of taking the concerns for co-workers' wages into account. However, doing so by paying equal wages to a group of agents may actually do more harm than good. As soon as agents differ in their performance, equal wages which seem to be a fair institution at first sight might be considered very unfair. While the discouraging effect of equal wages on hard-working agents has long been informally discussed (e.g., Milgrom and Roberts 1992, p. 418f), Abeler et al. (2010) provide controlled evidence in favor of this intuition. On the other hand, their study shows that adherence to the equity principle can lead to highly efficient workplace relations, even in the presence of contractual incompleteness.

\section{The role of communication}

In the study discussed in the previous section, the principal could not stipulate explicit pay-for-performance contracts for the workers. However, he could observe agents' individual performance levels and (voluntarily) pay them individual rewards in the IWT. It turned out that paying such individual-specific rewards in line with the equity principle was crucial for motivating agents to work hard. However, in many work environments, principals are not able to observe their subordinates' individual work effort and performance. Rather, they receive only aggregate information on the performance of the group of agents as a whole. This lack of information raises two central questions. First, does the absence of individual-specific information inhibit successful gift exchange between the principal and the agents, e.g., because it affects the principal's power to treat agents equitably? Second, are there means to circumvent such problems, i.e., is there a way for principals to become better informed on agents' individual contributions?

These are exactly the questions studied in a recent paper by Kleine and Kube (2010). As a natural candidate for how the principal could gather additional information on agents' individual effort levels, Kleine and Kube consider reporting systems in which agents communicate their own performance to the principal. Naturally, agents them- 
selves know their own effort and they can infer the performance of their co-worker when they additionally know the group performance. The crucial question is whether by asking agents about their individual performance, principals can obtain at least partially valuable information on agents' actual individual performance. Intuitively, agents' reports are "cheap talk" and principals cannot verify whether a given agent has reported own and others' performance truthfully. If agents anticipate that the principal rewards them according to the equity principle, they have immediate pecuniary incentives to overstate their own performance and to underreport the co-worker's performance.

There are two main motives that might prevent agents from deceiving and lead them to report individual performances truthfully. First, strategic considerations might generate long-run interests that work against the short-term incentive to deceive. Such strategic incentives can emerge through repeated interaction with the principal and co-worker, since agents fear that principals or co-workers might punish deception by withholding efforts or paying lower wages in the future. Psychological costs of lying are a second motive for truthful reporting. Recent research underlines the relevance of such "lying aversion" (Fischbacher and Heusi 2008; Gneezy 2005; Charness and Dufwenberg 2006). In their experiment, Kleine and Kube (2010) study whether these forces are strong enough to yield efficiency-enhancing effects of reporting systems, and thereby help to at least partially overcome the disadvantages of limited performance information from principals' perspective.

\subsection{Design}

Kleine and Kube conduct a laboratory experiment in which a principal interacts repeatedly with the same group of two agents. The work environment is again characterized by contractual incompleteness. Parameters are chosen as in Abeler et al. (2010) such that higher effort by agents is always socially efficient, but principals and agents have immediate material incentives to free-ride and avoid the cost of paying high wages or effort costs, respectively. A crucial design feature in the study of Kleine and Kube is that principals are not able to observe agents' individual efforts. Rather, princi- 
pals can only observe the sum of agents' effort when deciding on their wage payments. Furthermore, to study the influence of reputation on truth-telling and effort exertion, Kleine and Kube use a partner design with fixed worker-firm matches whereas Abeler et al. abstract from reputational concerns by randomly rematching players in different periods.

In this environment, Kleine and Kube examine the impact of one-way communication in the form of agents' reporting individual efforts to the principal. To study the influence of such "cheap-talk" reporting on the efficiency of gift exchange, Kleine and Kube study two treatment conditions which differ with respect to the reports that the principal obtains from the agents. In the baseline treatment (NoCom), no communication is allowed. While the principal can pay equal or different wages to both agents, he can base his decision only on the sum of efforts by both agents. In the communication treatment (Com), both agents simultaneously and independently report their effort levels. Agents have to report a feasible effort level, but they are not restricted to truthfully report their effort. The principal receives cheap-talk signals by both agents as well as the information on actual group performance. The principal therefore can base his wage payments on the actual sum of efforts and on the cheap-talk messages. Agents are not informed about the reports made by their co-worker.

\subsection{Results}

Kleine and Kube find that gift exchange can be established in repeated interactions between principals and agents. This basic result holds true for both treatments: despite the fact that principals are not able to observe agents' individual efforts, the implicit incentives in repeated interactions are strong enough to maintain efficient gift exchange. However, Kleine and Kube find remarkable differences between treatments in terms of overall efficiency. Figure 3 depicts average effort levels across treatments. Surprisingly, agents in the communication treatment exert significantly lower efforts than those in the baseline treatment. In treatment NoCom (Com), $23 \%(7 \%)$ of all effort choices are at the maximum, while $11 \%(28 \%)$ are at the minimum level. Overall, the baseline 


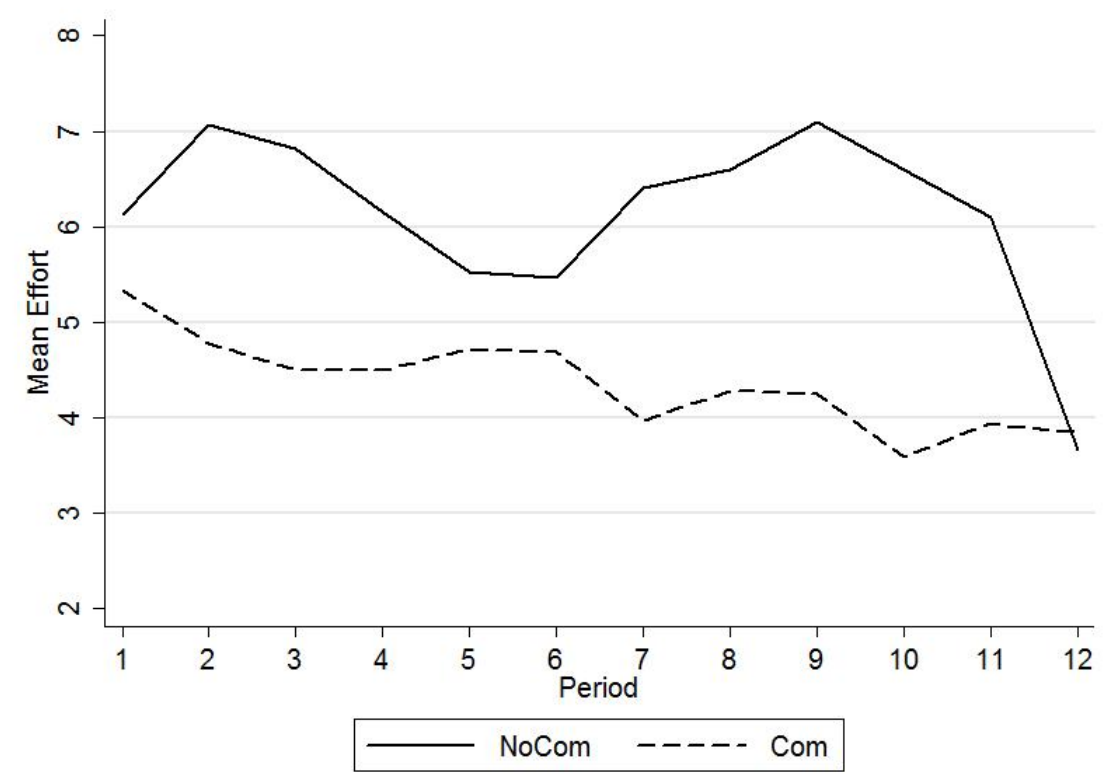

Figure 3: Kleine and Kube (2010): Effort over time

treatment without reporting possibilities exhibits a significantly higher performance than Com: $61 \%$ of possible efficiency gains are realized in NoCom and only about $43 \%$ in Com. These results raise two questions: First, why are gift-exchange relationships successfully established in NoCom even though principals lack the information necessary for (meaningful) wage discrimination? Second, why does efficiency decline when the principal receives additional information from the agents' reports in Com?

Concerning the first question, because of the identical parameterizations and subject pools it is illustrative to compare the behavior in NoCom to the results of the individual wage (IWT) and equal wage treatment (EWT) reported in Abeler et al. (2010). Effort levels in NoCom are substantially higher than in EWT. This is interesting because frequent equity-norm violations are a driving force behind agents' behavior in EWT, and these violations might occur in NoCom as well. In fact, it is observed that i) firms in NoCom regularly choose to pay equal wages which would violate the equity principle whenever agents differ in their effort levels and ii) agents' reactions to equity norm violations are very similar in EWT and NoCom. However, while actual violations are very frequent in EWT ( $90 \%$ of the time), they only occur in $65 \%$ of all cases in NoCom. 
In the other instances, principal and agents manage to adhere to an equity norm. Many agents in NoCom thus seem to realize that norm violations can only be avoided if they choose identical efforts. The partner matching additionally enables them to coordinate on equal (and high) effort levels, which in turn explains the relatively high degree of efficiency in NoCom. Yet it should be noted that, although the repeated interaction facilitates the use of gift-exchange for overcoming the problems of contractual incompleteness, it does not seem to be central. For example, firms in IWT do much better than in NoCom even though reputational concerns cannot play a role there due to the stranger matching procedure. This further underlines the importance of firms being able to discriminate wages between workers in a sensible way.

But why does communication lead to lower efficiency in Com compared to NoCom? Principals could systematically use agents' reports as an additional source of information for the wage setting decision. This might positively affect agents' effort if it helps to reduce equity norm violations. These positive consequences are in fact observed in Com. Principals take the reports into account, and equity norm violations are reduced by about $29 \%$. However, the reporting possibilities also lead to negative effects, which offset and even exceed the positive aspects. These negative effects are caused by (the anticipation of) agents misreporting their effort choice. In $56 \%$ of all cases, at least one agent overstates his or her effort choice; principals observe this because the sum of reported efforts does not match the sum of actual efforts. As a consequence, reporting spreads additional distrust in the principal-team setting, in the vertical principal-agent relationship as well as in the horizontal relationship within the team. On the one hand, this is reflected in the observation that principals significantly reduce their wage payments after they receive a misreport. On the other hand, negative effort reactions after equity norm violations are more pronounced in Com than in NoCom-which might be due to the relatively unkind behavior of the principals after a misreport, but most likely also due to agents' mutual concerns that the co-worker might lie at their cost. Reporting thus comes at the cost of distrust and frustration among the team members.

The results in Kleine and Kube (2010) clearly demonstrate that certain communica- 
tion structures might be counterproductive. If principals in organizations ask workers about their individual contributions to team performance and want to adapt their wages or bonuses accordingly, the reported evidence suggests that the reporting mechanism should be chosen carefully. Unfavorable communication structures may reduce the power of gift exchange and reduce the agents' motivation to exert high effort in the team. It might be better to refrain from reports on individual performance, as long as the accompanied communication structures cannot effectively prevent the development of distrust among the concerned parties.

\section{4 (No) impact of personal relations}

The previous studies highlight that it is possible to successfully establish efficient giftexchange relationships in multi-worker firms. A necessary condition seems to be that the wage payments are perceived as fair by the workers, which in the context of multiworker firms includes that wages must be compatible with a norm of equity. In the preceding studies, this meant that hard-working agents should earn more than lazy agents. This interpretation is straightforward if all players are anonymous strangers, as is the case in most lab experiments in economics.

Yet, actual employment relationships are characterized by a rich set of personal relationships between members of the firm. Social ties are frequently observed between direct co-workers but also across layers of a firm's hierarchy, i.e., between principals and agents. Particularly the latter relationships might affect the effective use of gift exchange to mitigate moral hazard under incomplete contracts. First, it might happen that those workers who maintain a close relationship to the principal work harder, simply because they have sentiments for that person. ${ }^{5}$ At the same time, social ties might change the workers' perception of what constitutes a fair wage. Moreover, personal relations between supervisors and certain subordinates could have negative effects on other

\footnotetext{
${ }^{5}$ In a sense, this is basically part of the original idea of Akerlof (1982) on gift-exchange, namely that "it is natural that persons have utility for making gifts to institutions for which they have sentiment (p.550)".
} 
workers, for example if a principal favors the workers with whom he maintains close relationships, or if the other workers perceive the treatment of the principal's acquaintances as an act of nepotism. This could lead to (perceived) equity-norm violations and thus hamper successful gift-exchange.

To explore these effects, Schneider and Kube (2006) conduct a laboratory experiment in which, as in the studies described in the previous sections, one principal interacts with two agents. The crucial feature of their experiment is that one of the agents is a real-life friend of the principal, whereas the other agent is an anonymous stranger. This novel feature, combined with a treatment variation on transparency versus secrecy of co-workers' wages, allows them to study under controlled laboratory conditions how personal relationships affect gift exchange.

\subsection{Design}

Except for some parameter values, the game studied by Schneider and Kube is similar to the individual wage treatment in Abeler et al. (2010). Each firm consists of one principal and two agents who play a reversed gift-exchange game. On a first stage, agents simultaneously decide how much costly effort $e_{i}$ to exert (with $e_{i} \in\{0,1, \ldots, 9\}$ ). On a second stage, the principal observes agents' effort choices and can pay an individual wage $w_{i}$ to each agent. Finally, payoffs are realized: agents earn their individual wage minus their effort costs, and the principal earns what is produced by the agents' effort minus the wage payments.

In each firm, the principal and one agent are real-life friends while the second agent is a stranger who is matched anonymously in each firm. ${ }^{6}$ Each group interacts repeatedly for 12 rounds in a partner design, i.e., the groups of three stay the same throughout the experiment. A repeated game is necessary to analyze the influence of friendship on participants' fairness perceptions and behavior. Friends, of course, need to remain paired in the same group. Moreover, the repeated partner design allows for a more

\footnotetext{
${ }^{6}$ In the following, the anonymous agent will be referred to as "stranger" and the acquainted agent as "friend".
} 
direct response of an agent to his or her wage payment.

Schneider and Kube study two treatment variations that differ in the degree of wage secrecy between the agents. In the first treatment, wages are fully transparent, i.e., both agents can observe the wage of their co-worker in every period. In the second treatment, agents only observe each others' effort but not their wage or payoff. In both treatments, the subgame perfect Nash equilibrium under the assumption of rational and selfish individuals is again to pay minimal wages and to exert minimal efforts. As before it would be socially efficient to exert maximal efforts given the cost and production functions.

\subsection{Results}

In line with the results reported in Section 2 and Section 3, Schneider and Kube observe strong indications of reciprocal behavior. Higher effort on average leads to a higher wage and to a higher payoff. As can be seen in Figure 4, the positive correlation between effort and wages is equally strong for friends and strangers. The overall correlation between effort and wages under public wages is $\rho=.76$ for the friend and $\rho=.71$ for the stranger. It is slightly less pronounced under wage secrecy with $\rho=.62$ for the friend and $\rho=.41$ for the stranger. The effort levels are remarkably high in both treatments. Friends (strangers) provide on average an effort of 7.4 (7.3) under public wages and $8.1(8.2)$ in the case of wage secrecy. There are no significant differences in efforts, neither between treatments, nor between friend and stranger. Overall, 85\% of the possible efficiency gains are realized - although explicit contract enforcement is not feasible.

Interestingly, also no significant differences in wages or in payoffs can be found. The average wage paid to a friend (stranger) is 48 (44) under public wages and 51 (53) when wages are private information. Thus even under a wage-secrecy regime, only weak signs of nepotism are observed by Schneider and Kube. ${ }^{7}$ The principal

\footnotetext{
${ }^{7}$ There are only 16 instances in which agents choose equal effort levels but the friend is paid a higher wage. In these cases, the wage payment is on average $14 \%$ higher than the stranger's wage. It should
} 

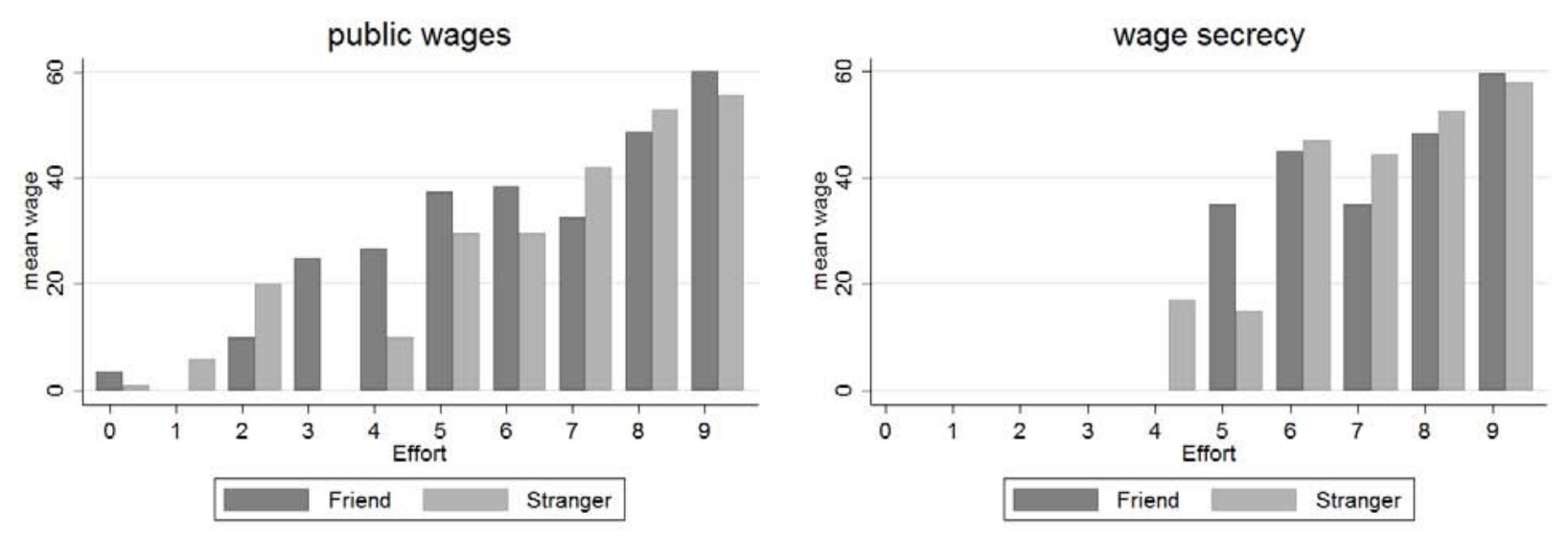

Figure 4: Schneider and Kube (2006): Effort-wage relationships

treats his acquaintance almost in the same way as he treats the stranger. This is also underlined by data from a questionnaire that was administered to the subjects after the experiment. Principals uniformly and strongly agree to the statement "I treated the agents equally", and agents strongly disagree to the statement "The other agent was treated better". The findings thus suggest that a norm of equity is highly valued by both, the principal and the agents. In fact, violations of the equity norm happen only very rarely. If they occur, they have considerable effects on agents' behavior because violations immediately lead to lower levels of effort in the following round. Principals seem to recognize or even anticipate this (an observation which is shared by the previously reported studies). They abstain from favoring their friends, in particular when other agents could observe it. As a consequence, gift exchange again successfully mitigates the problems of implicit contracts. This suggests that potential problems arising from the presence of personal relationships across the firm's hierarchical layers can be overcome. Moreover, the tentative evidence reported by Schneider and Kube indicates that the use of implicit contracts in combination with wage transparency can pose a limit on nepotism.

ne noted, however, that side-payments between the principal and his friend cannot be precluded after subjects have left the laboratory. 


\section{Social preferences in the presence of explicit in- centives}

The study presented in the previous section looked at heterogeneity among agents with respect to personal relationships. From an purely economic perspective, such a form of heterogeneity should not give rise to wage discrimination in multi-worker firms. By contrast, if agents differ in terms of ability and performance, incentive schemes in organizations should try to account for this, e.g., by a non-uniform distribution of payments among the agents. The study by Abeler et al. (2010) has demonstrated this for the case of implicit work contracts. But how do wage differences and social preferences interact in the case of explicit performance incentives that discriminate between agents? Again, as long as the discrimination is based on individual differences, i.e., as long as unequal agents are rewarded unequally, there should be little scope for fairness considerations to induce dissonance among the agents. ${ }^{8}$ But what if equal agents are treated unequally?

Such an incentive scheme might seem inappropriate at first sight. However, a recent theoretical model developed by Winter (2004) shows that - depending on the form of the production function - situations might exist where this is part of the optimal incentive mechanism. This surprising theoretical result, derived under the standard assumptions of fully rational, self-centered and money-maximizing behavior, seems to stand in sharp contrast to the implications from research on fairness and equity preferences, whose bottom line is that "even a small intrinsic concern for justice, .. may have significant effects on .. wage structure" (Konow 2000, p. 1089; see also Bolton and Ockenfels 2000; Fehr and Schmidt 1999; Mowday 1991; Young 1994 or Selten 1978). Goerg et al. (2010) test within the framework of Winter's model whether the psychological

\footnotetext{
${ }^{8} \mathrm{~A}$ necessary assumption for this statement is that agents are aware of the individual differences and do not misperceive the direction of the differences. This might, for example, not hold true if agents are overconfident about their own performance (see Ross and Sicoly (1979) for early evidence on overconfidence about contribution to a joint project).
} 
cost of the inequality induced by wage discrimination decreases the efficiency of the theoretically optimal mechanism.

\subsection{Winter's Model}

The general model analyzed by Winter (2004) features $n$ agents who work on a joint project. The agents decide simultaneously and independently whether they work and provide positive effort or whether they shirk and provide zero effort. Exerting effort is costly for the agents, with costs being equal across all agents. Individual effort is assumed to be non-observable and non-contractible. Instead, agents' rewards are contingent on the success of the project as a whole. That is, agents receive individual rewards if the group project succeeds and 0 if the project is not successful. The probability of the project's success depends on the total number of agents who exert effort. Throughout their experiments, Goerg et al. (2010) assume that the probability of project success is strictly increasing in the number of agents who exert effort. The production function can have two basic shapes that differ in whether returns to scale are increasing or decreasing. Increasing returns to scale mean that the returns of an additional agent who exerts effort (in terms of project success probability) increases in the number of agents who have already exerted effort. That is, efforts are complementary in the sense that additional units of effort are more valuable when many agents have already exerted effort. In contrast, a production function characterized by decreasing returns to scale means that efforts of different agents are substitutes: the increase in the project success probability is highest for the first agent who provides effort, and the incremental increase in the success probability gets lower for every additional unit of effort.

A reward mechanism, defining the rewards for each worker, is said to be strongly incentive-inducing if it induces all agents to exert effort as a unique Nash equilibrium, and it is optimal if it does so at minimal cost from a principal's perspective. The mechanism is symmetric if rewards are constant across all agents and it is discriminating if rewards differ across agents. It can be shown that a symmetric, optimal, strongly 
incentive-inducing mechanism exists if and only if the production function is one of substitutability. In contrast, a production function of complementarity implies that the optimal, strongly incentive-inducing mechanism is fully discriminating; that is, agents should optimally be paid different rewards even if they are perfectly symmetric.

A technology of increasing returns to scale is a sufficient, but not a necessary, condition for full discrimination. In fact, it is only necessary that an agent's incentive to exert effort increases with the number of other agents who do so, which for example might also be caused by psychological effects like peer pressure (see Kandel and Lazear 1992; Barron and Gjerde 1997; Falk and Ichino 2006 or Mas and Moretti 2009 and the references therein).

\subsection{Design}

Goerg et al. experimentally test the key predictions of Winter's model, namely whether subjects' behavior is indeed sensitive to the externalities given by the production technology, and whether a major incentive advantage of discriminating among perfectly identical agents really exists; or if the psychological costs induced by the unequal treatment of equals drive a wedge between the initially predicted and the actually observed efficiency.

Ideally, these questions would be examined with "cloned" workers acting in "cloned" work environments which differ only with respect to the production function and the reward schemes. To come close to this ideal world, Goerg et al. introduce a simple laboratory experiment that allows them to analyze the interaction between production function, equity considerations, and reward schemes, while at the same time ensuring that agents are perfectly identical. In the experiment, three players work on a joint project and exert costly efforts. Their total sum of effort determines the number of units of a good produced by the joint project for a given production function. The payoff of a player is given by the productivity (i.e., the number of units produced by the group) multiplied by an individual reward, minus the cost of effort. Goerg et al. create four different treatments by manipulating the characteristics of the production 


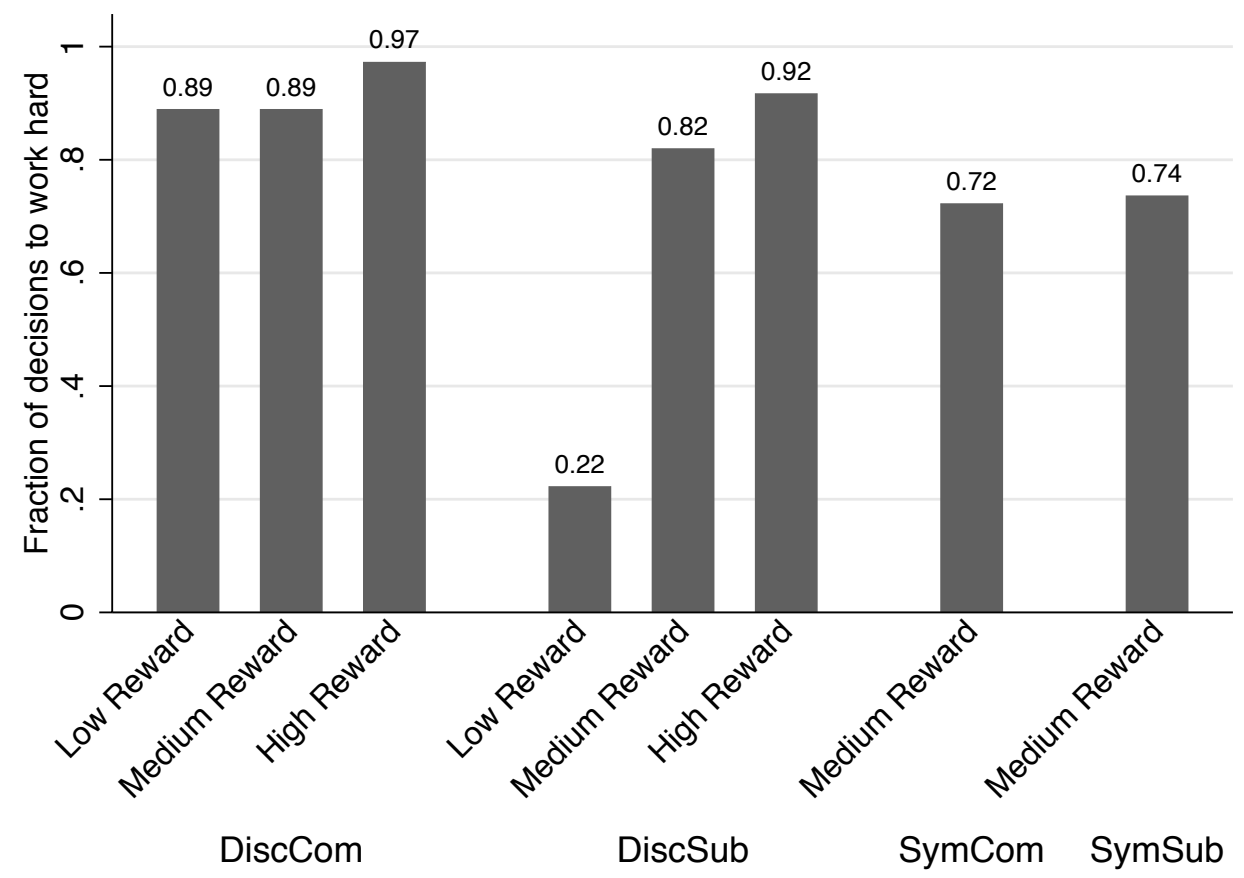

Figure 5: Goerg et al. (2010): Effort decisions for each worker type over the different reward mechanisms (Disc: Discriminating; Sym: Symmetric) and production functions (Com: Complementarity; Sub: Substitutability).

function (either a function of complementarity or of substitutability) as well as of the reward scheme (either a symmetric or a discriminating mechanism), while at the same time keeping the sum of rewards per produced unit constant.

\section{$5.3 \quad$ Results}

As predicted by Winter's model, the subjects in the experiment of Goerg et al. respond to the shape of the production function. Under a production function of complementarity, the use of a symmetric reward scheme elicits significantly lower efforts and efficiency than the use of a cost-equivalent discriminating reward scheme. The same discriminating reward scheme yields lower efforts when it is used under a production function of substitutability.

Figure 5 reveals that in the case of a discriminating reward scheme and a production function of complementarity even the worker with the lowest reward exerts high amounts of effort. The main reason for this is that asymmetric rewards facilitate coordination because workers can anticipate that those who have high stakes at hand will certainly exert effort, which in turn incentivizes the other worker to exert effort as well. 
In real-life organizations, this discrimination is often implemented through nonmonetary rewards, e.g., prestige, or by using artificial classifications or (job) titles for seemingly similar tasks, e.g., "Project Head" or "Team Captain". 9 It is often hidden to avoid negative reactions of inequality-averse workers. Pay discrimination can also be institutionalized by an internal (pay) structure. For example, lawyers, consultants and accountants are paid according to seniority. This special form of discrimination creates common knowledge about the stakes that everyone has in the project's success, and thus fosters cooperation and coordination; at the same time it does not invoke equity concerns because everyone knows that his turn will come to be senior partner. The experimental results show that under a production function of complementarity even transparent discrimination contributes to efficiency.

Goerg et al. point out that their results should not be taken as arguments against the importance of fairness considerations in general. The results from the treatments with a production function of substitutability and the results from Abeler et al. (2010), discussed in Section 2, show that horizontal fairness considerations among workers do in fact matter. But Goerg et al. (2010) argue that under certain circumstances the advantage of the coordination induced by the production function outweighs such considerations. Designing (production) tasks in a way that makes workers' effort complements rather than substitutes may lead to major efficiency gains. Insofar as peer pressure constitutes a complementarity in effort exertion, the strengthening of social ties among the workforce alone might have a strong impact on productivity.

\section{Concluding remarks}

Our purpose in this paper was to illustrate how research in experimental economics can contribute to a better understanding of the interdependencies between equity and

\footnotetext{
${ }^{9}$ The "Team Captain", as the one carrying the responsibility and possible blame for unsuccessful results, is highly motivated to exert effort. Therefore, he functions to incentivize the other team members in the same way as the high-reward agent in their model induces cooperation and high productivity. See also Winter (2004, p. 769)
} 
efficiency in employment relations that are characterized by contractual incompleteness. We have focused on a selection of papers that study situations in which one principal interacts with several agents. These are particularly interesting not only because of their higher degree of realism compared to bilateral gift-exchange relations, but also because equity concerns become more complex and more interesting when there is both a vertical and a horizontal dimension of fairness. Overall, the findings discussed in this paper suggest that efficiency-enhancing gift exchange can work well in multi-agent firms when basic equity considerations are taken into account.

In this paper, we could only discuss a small selection of studies that does not cover the wealth of empirical results obtained in recent years. The field of experimental research in labor economics is flourishing, and the body of literature keeps growing rapidly (see Charness and Kuhn 2011 and List and Rasul 2011 for recent comprehensive surveys). We conclude by discussing several particularly relevant recent papers and how they relate to the results presented in this paper.

The studies discussed in the previous sections show that social comparisons, fairness perceptions and subsequent behavioral reactions determine the success of gift-exchange relationships. This has also been illustrated in work environments outside the laboratory (Kube et al. 2010; Kube et al. 2011; Cohn et al. 2011; but see also Gneezy and List 2006). The general importance of social comparison and equity-norm violations is also underlined by recent neurophysiological evidence (Fließbach et al. 2007; Dohmen et al. 2011).

A second important message from the evidence presented in this paper is that wage differentiation per se does not imply that workers feel treated unfairly as shown in sections 2 and 5. A much more nuanced picture that goes beyond the notion of simple one-dimensional wage comparison effects has emerged from recent research. The perception of a given wage crucially depends on the information workers have, e.g., on the production technology or their co-workers' effort and productivity. A distinctive advantage of an experimental approach is that information conditions and other important factors of the production process can be varied exogenously, which in turn allows 
identifying causal influences of individual factors as well as potential interdependencies between them. For instance, Charness and Kuhn (2007) study the impact of co-worker comparison and wage secrecy in a situation where co-workers differ in their inherent productivity rather than their actual performance. They find that wage discrimination is not generally considered unfair by agents. Rather, agents tend to accept pay differences if these are rationalized by differences in ability. In a setup similar to the one considered in Section 4, Brandts and Solà (2010) study how personal relations between a principal and one agent affect workplace performance. They show that principals tend to favor the agents to whom they have closer social ties, but that such differential treatment is also justified since the agent with closer personal relations reciprocates more strongly. Consequently, favoring of friends does not affect the performance of agents with weaker social ties in the experiment of Brandts and Solà (2010). In a similar vein, Gächter and Thöni (2010) show that reactions to wage discrimination depend on the underlying reasons for pay discrimination rather than to the resulting payoff differences per se. Gächter et al. (2011) also underline the notion that wage comparison alone does not affect gift exchange relationships. Rather, social comparisons between co-workers seem to be multi-dimensional, taking into account information on others' performance as well as their wage level. An important implication of these results as well as those in Section 3 is that the success of gift-exchange relations can under certain circumstances be influenced by manipulating the flow of information.

Inspired by empirical findings, a growing number of theoretical models analyzes economic incentives in the workplace, taking social preferences and social comparison processes into account. For instance, Kölle et al. (2011) analyze the consequences of inequality in ex-ante and ex-post payments and the resulting incentives for inequityaverse agents to engage in a team production task. Dur and Sol (2010) discuss the influence of financial incentives on the work climate when agents do not only engage in productive activities, but also build up altruistic sentiments for their co-workers via social interaction in the workplace. Related to the topics discussed in Section 3 and Section 4, Sol (2010) has recently developed a theoretical model in which agents 
have superior information on the performance of co-workers. He analyzes how agents' preferences for truth-telling, their interpersonal relations to co-workers, and financial incentives influence the value of cheap-talk reporting systems for the principal.

Recent theoretical and empirical research has contributed a lot to our understanding of gift exchange and the relation between equity and efficiency when contracts are incomplete. The small selection of this work presented here already highlights the importance of looking at multi- rather than single-worker firms and models. Understanding what is perceived as fair becomes much more complicated when more than one worker is involved. The examples discussed above illustrate some potential caveats to be kept in mind when designing incentive schemes for more than one worker. More research is called for, e.g., regarding environments where reciprocity must not necessarily manifest itself in the form of higher effort levels but rather in lower absenteeism, higher loyalty, or lower turn-over. 


\section{References}

Abeler, Johannes, Steffen Altmann, Sebastian Kube and Matthias Wibral (2010): "Gift Exchange and Workers' Fairness Concerns: When Equality Is Unfair." Journal of the European Economic Association, 8:1299-1324.

Adams, J. Stacy (1963): "Wage Inequities, Productivity and Work Quality." Industrial Relations, 3:9-16.

Adams, J. Stacy (1965): "Inequity in Social Exchange." In Berkowitz, Leonard, editor, Advances in Experimental Social Psychology, volume 2, pages 267-299. Academic Press, New York.

Akerlof, George A. (1982): "Labor Contracts as Partial Gift Exchange." The Quarterly Journal of Economics, 97:543-569.

Baker, George, Robert Gibbons and Kevin J. Murphy (1992): "Relational Contracts and the Theory of the Firm." The Quarterly Journal of Economics, 117:39-84.

Baker, George, Michael C. Jensen and Kevin J. Murphy (1988): "Compensation and Incentives: Practice vs. Theory." Journal of Finance, 43:593-616.

Barron, John E. and Kathy Paulson Gjerde (1997): "Peer Pressure in an Agency Relationship." Journal of Labor Economics, 15:234-254.

Bewley, Truman F. (1999): Why Wages Don't Fall During a Recession. Harvard University Press, Cambridge, MA.

Bolton, Gary E. and Axel Ockenfels (2000): "ERC: A Theory of Equity, Reciprocity, and Competition." American Economic Review, 90:166-193.

Brandts, Jordi and Carles Solà (2010): "Personal Relations and their Effect on Behavior in an Organizational Setting: An Experimental Study." Journal of Economic Behavior and Organization, 73:243-253. 
Charness, Gary and Martin Dufwenberg (2006): "Promises and Partnership." Econometrica, 74:1579-1601.

Charness, Gary and Peter Kuhn (2007): "Does Pay Inequality Affect Worker Effort? Experimental Evidence." Journal of Labor Economics, 25:693-723.

Charness, Gary and Peter J. Kuhn (2011): "Lab Labor: What Can Labor Economists Learn from the Lab?" In Ashenfelter, Orley and David Card, editors, Handbook of Labor Economics, volume 4, pages 229-330. Elsevier, Amsterdam.

Cohn, Alain, Ernst Fehr, Benedikt Herrmann and Frédéric Schneider (2011): "Social Comparison in the Workplace: Evidence from a Field Experiment." IZA Discussion Paper, 5550.

Deci, Edward L. (1971): "Effects of Externally Mediated Rewards on Intrinsic Motivation." Journal of Personality and Social Psychology, 18:105-115.

Dohmen, Thomas, Armin Falk, Klaus Fliessbach, Uwe Sunde and Bernd Weber (2011): "Relative versus Absolute Income, Joy of Winning, and Gender: Brain Imaging Evidence." Journal of Public Economics, forthcoming.

Dur, Robert and Joeri Sol (2010): "Social interaction, Co-Worker Altruism, and Incentives." Games and Economic Behavior, 69:293-301.

Erev, Ido, Gary Bornstein and Rachel Galili (1993): "Constructive Intergroup Competition as a Solution to the Free Rider Problem: A Field Experiment." Journal of Experimental Social Psychology, 29:463-478.

Falk, Armin and James J. Heckman (2009): "Lab Experiments Are a Major Source of Knowledge in the Social Sciences." Science, 326:535-538.

Falk, Armin and Andrea Ichino (2006): "Clean Evidence on Peer Effects." Journal of Labor Economics, 24:39-57. 
Falk, Armin and Michael Kosfeld (2006): "The Hidden Cost of Control." American Economic Review, 96:1611-1630.

Fama, Eugene F. (1980): "Agency Problems and the Theory of the Firm." Journal of Political Economy, 88:288-307.

Fehr, E., G. Kirchsteiger and A. Riedl (1993): "Does Fairness Prevent Market Clearing? An Experimental Investigation." Quarterly Journal of Economics, 108:437-460.

Fehr, Ernst and Armin Falk (2002): "Psychological Foundations of Incentives." European Economic Review, 46:687-724.

Fehr, Ernst, Simon Gächter and Georg Kirchsteiger (1997): "Reciprocity as a Contract Enforcement Device: Experimental Evidence." Econometrica, 65:833-860.

Fehr, Ernst and Klaus M. Schmidt (1999): "A Theory of Fairness, Competition and Cooperation." The Quarterly Journal of Economics, 114:817-868.

Fischbacher, Urs and Franziska Heusi (2008): "Lies in Disguise." Thurgau Institute Working Paper, 2008-040.

Fließbach, Klaus, Bernd Weber, Peter Trautner, Thomas Dohmen, Uwe Sunde, Christian Elger and Armin Falk (2007): "Social Comparison Affects Reward-Related Brain Activity in the Human Ventral Striatum." Science, 318:1305-1308.

Gächter, Simon, Daniele Nosenzo and Martin Sefton (2011): "The Impact of Social Comparisons on Reciprocity." Scandinavian Journal of Economics, forthcoming.

Gächter, Simon and Christian Thöni (2010): "Social Comparison and Performance: Experimental Evidence on the Fair Wage-Effort Hypothesis." Journal of Economic Behavior and Organization, 76:531-543.

Gibbons, Robert and Kevin J. Murphy (1992): "Optimal Incentive Contracts in the Presence of Career Concerns: Theory and Evidence." Journal of Political Economy, 100:468-505. 
Gneezy, Uri (2005): "Deception: The Role of Consequences." American Economic Review, 95:384-394.

Gneezy, Uri and John A. List (2006): "Putting Behavioral Economics to Work: Testing for Gift Exchange in Labor Markets Using Field Experiments." Econometrica, $74: 1365-1384$.

Gneezy, Uri and Aldo Rustichini (2000): "Pay Enough or Don't Pay at all." Quarterly Journal of Economics, 115:791-810.

Goerg, Sebastian J., Sebastian Kube and Ro’i Zultan (2010): “Treating Equals Unequally: Incentives in Teams, Workers' Motivation, and Production Technology." Journal of Labor Economics, 28:747-772.

Holmström, Bengt (1982): "Moral Hazard In Teams." Bell Journal Of Economics, 13:324-340.

Holmström, Bengt (1999): "Managerial Incentive Problems: A Dynamic Perspective." Review of Economic Studies, 66:169-182.

Holmström, Bengt and Paul Milgrom (1991): "Multitask Principal-Agent Analyses: Incentive Contracts, Asset Ownership, and Job Design." Journal of Law, Economics, and Organization, 7:24-52.

Kandel, Eugene and Edward P. Lazear (1992): "Peer Pressure and Partnerships." Journal of Political Economy, 100:801-817.

Kleine, Marco and Sebastian Kube (2010): "Communication and Trust in PrincipalTeam Relationships: Experimental Evidence." mimeo.

Kölle, Felix, Dirk Sliwka and Nannan Zhou (2011): "Inequality, Inequity Aversion, and the Provision of Public Goods." IZA Discussion Paper, 5514.

Knez, Marc and Duncan Simester (2001): "Firm-Wide Incentives and Mutual Monitoring at Continental Airlines." Journal of Labor Economics, 19:743-772. 
Konow, James (2000): "Fair shares: Accountability and cognitive dissonance in allocation decisions." American Economic Review, 90:1072-1091.

Kube, Sebastian, Michel A. Marechal and Clemens Puppe (2010): "Do Wage Cuts Damage Work Morale? Evidence from a Natural Field Experiment." IEW Working Paper.

Kube, Sebastian, Michel A. Marechal and Clemens Puppe (2011): "The Currency of Reciprocity - Gift-Exchange in the Workplace." American Economic Review, forthcoming.

Lazear, Edward P. and Sherwin Rosen (1981): "Rank-Order Tournaments as Optimum Labor Contracts." Journal of Political Economy, 89:841-864.

Levitt, Steven D. and John A. List (2007): "What Do Laboratory Experiments Measuring Social Preferences Reveal About the Real World." Journal of Economic Perspectives, 21:153-174.

List, John A. and Imran Rasul (2011): "Field Experiments in Labor Economics." In Ashenfelter, Orley and David Card, editors, Handbook of Labor Economics, volume 4, pages 103-228. Elsevier, Amsterdam.

MacLeod, W. Bentley and James M. Malcomson (1989): "Implicit Contracts, Incentive Compatibility, and Involuntary Unemployment." Econometrica, 57:447-480.

Mas, Alexander and Enrico Moretti (2009): "Peers at Work." American Economic Review, 99:112-145.

Medoff, James L. and Katharine G. Abraham (1980): "Experience, Performance, and Earnings." The Quarterly Journal of Economics, 95:703-36.

Milgrom, Paul and John Roberts (1992): Economics, Organization and Management. Prentice Hall, Upper Saddle River, New Jersey. 
Mowday, Richard T. (1991): "Equity Theory Predictions of Behavior in Organizations." In Steers, Richard M. and Lyman W. Porter, editors, Motivation and Work Behavior, volume 5th Edition, pages 111-131. McGraw-Hill, New York.

Pfeffer, Jeffrey and Nancy Langton (1993): "The Effect of Wage Dispersion on Satisfaction, Productivity, and Working Collaboratively: Evidence from College and University Faculty." Administrative Science Quarterly, 38:382-407.

Prendergast, Canice (1999): "The Provision of Incentives in Firms." Journal of Economic Literature, 37:7-63.

Rosen, Sherwin (1986): "Prizes and Incentives in Elimination Tournaments." American Economic Review, 76:701-715.

Ross, Michael and Fiore Sicoly (1979): "Egocentric biases in availability and attribution." Journal of Personality and Social Psychology, 37:322-336.

Schneider, Simone and Sebastian Kube (2006): "Personal relations and implicit contracts - An experimental study." mimeo.

Selten, Reinhard (1978): "The Equity Priciple in Economic Behavior." In Gottinger, Hans-Werner and Werner Leinfellner, editors, Decision Theory and Social Ethics: Issues in Social Choice, pages 289-301. D. Reidel Publishing Company, Dordrecht.

Sol, Joeri (2010): "Peer Evaluation: Incentives and Co-Worker Relations." Tinbergen Institute Discussion Paper, 2010-055.

Winter, Eyal (2004): "Incentives and Discrimination." American Economic Review, 94:764-773.

Young, Peyton (1994): Equity in Theory and Practice. Princeton University Press. 